\title{
Magnetic characteristics of lake sediments in Qiangyong Co Lake, southern Tibetan Plateau and their application to the evaluation of mercury deposition
}

\author{
GAO Xing ${ }^{1}$, KANG Shichang ${ }^{2}$, LIU Qingsong ${ }^{3}$, CHEN Pengfei ${ }^{2}$, DUAN Zongqi ${ }^{1,4}$ \\ 1. State Key Laboratory of Resources and Environmental Information System, Institute of Geographic Sciences \\ and Natural Resources Research, CAS, Beijing 100101, China; \\ 2. State Key Laboratory of Cryospheric Science, Northwest Institute of Eco-Environment and Resources, CAS, \\ Lanzhou 730000, China; \\ 3. Department of Ocean Science and Engineering, Southern University of Science and Technology, Shenzhen \\ 518055, Guangdong, China; \\ 4. The Geographical Society of China, Beijing 100101, China
}

\begin{abstract}
Heavy metals, one of the most toxic classes of pollutants, are resistant to degradation and harmful to the biological environment. The lakes that have developed on the Tibetan Plateau are ideal regions to investigate historic heavy metal pollution, particularly through the use of the reliable ${ }^{210} \mathrm{~Pb}$ dating technique. Environmental magnetism has been successfully applied to estimate heavy metal pollution in different environmental systems due to its characteristics of simple processing steps, good sensitivity, and non-destructibility. However, it has not yet been applied to assess heavy metal pollution in lake sediments on the Tibetan Plateau. A series of environmental magnetic investigations of Qiangyong Co Lake sediments (southern Tibetan Plateau) was therefore conducted to explore the relationship between magnetic minerals and mercury $(\mathrm{Hg})$ concentrations. The results showed that the magnetic mineral species in lake sediments remained stable, with similar levels of four different components from 1899 to 2011. However, the proportion of component 1 (C1, hematite) increased continuously with the corresponding decrease in the proportion of C2 (goethite), while the proportions of C3 and C4 (magnetite) did not change significantly. As a result, the bulk magnetic signals (e.g., SIRM and $\chi_{\mathrm{If}}$ ) were unsuitable for the evaluation of the $\mathrm{Hg}$ concentration; however, the proportion of hematite had a strong positive correlation with the $\mathrm{Hg}$ concentration. It is possible that the Qiangyong Glacier (the main water supply for Qiangyong Co Lake) has experienced faster melting with global and local warming, and the $\mathrm{Hg}$ trapped in cryoconite and ice was released. Hematite, with a large specific surface area, has a strong capacity for absorbing $\mathrm{Hg}$, and both materials are ultimately transported to Qiangyong Co Lake. The
\end{abstract}

Received: 2019-11-28 Accepted: 2020-05-21

Foundation: National Natural Science Foundation of China, No.41506075, No.41430962, No.41574036, No.41705132

Author: Gao Xing, Professor, specialized in earthquake and geological disaster, and environmental magnetism.

E-mail: gxing@igsnrr.ac.cn

"Corresponding author: Duan Zongqi, PhD and Assistant Professor, specialized in environmental magnetism and its application to sedimentary evolution. E-mail: duanzq@igsnrr.ac.cn 
proportion of hematite in a sample is therefore a suitable semi-quantitative proxy that can be used to evaluate the $\mathrm{Hg}$ concentration in Qiangyong Co Lake sediments. This study confirmed that the variation of magnetic minerals can provide a new method to estimate the variation of $\mathrm{Hg}$ concentrations and to study the process of $\mathrm{Hg}$ deposition in lakes in the southern Tibetan Plateau on the basis of a detailed environmental magnetic analysis.

Keywords: southern Tibetan Plateau; Qiangyong Co Lake; environmental magnetism; mercury (Hg) deposition

\section{Introduction}

Due to its high altitude, the Tibetan Plateau (TP) is known as the world's roof and is considered the third pole (Zheng and Yao, 2004). Sparse population on the TP is a consequence of its unique climatic ecological environment. There are relatively few agricultural and industrial activities on the TP; thus, the area is presumed to be largely unaffected by human activity and is considered a sensitive region for monitoring the atmospheric environment (Qiu, 2008). Even in Lhasa, the capital and most developed city of this region, the air quality has been good for many years (Yin et al., 2019). However, under the action of Westerlies and the Asian monsoon (Zhu et al., 2015; Yao et al., 2017; Guo et al., 2019), pollutants from outside the TP are transported into the region by dry and wet deposition (Li et al., 2007; Cong et al., 2010; Kang et al., 2019). For example, persistent organic pollutants (Zhang et al., 2003; Wang et al., 2016), heavy metals (Yang et al., 2010; Kang et al., 2016; Huang et al., 2019), polycyclic aromatic hydrocarbons (Xie et al., 2014), organic molecular tracers (Wan et al., 2017), and black carbon (Xu et al., 2009; Li et al., 2016; Wu et al., 2018; Chen et al., 2019) have been detected in aerosol particles, dust, snow, surface soil, ice cores, and lake sediments.

Due to their high levels of toxicity, long half-life, and refractory properties, heavy metal pollutants are considered to be one of the most harmful pollutants, and can pose a tremendous hazard to the ecological environment (Liu et al., 2016; Mamattursun et al., 2017). Previous studies have shown that some of the heavy metal pollution in the TP is due to traffic activity (Zhang et al., 2012) and fertilizer and pesticide use (Sun et al., 2016) inside the plateau, but the majority is from extraneous atmospheric particulate (dust and aerosol particles) inputs (Xiao et al., 2000; Zhang et al., 2003; Yang et al., 2010; Guo et al., 2016; Kang et al., 2016; Huang et al., 2019). The most commonly used experimental analysis method is the decomposition of samples by the Community Bureau of Reference (BCR) three-step sequential extraction procedure, followed by an inductively coupled plasma mass spectrometry (ICP-MS) analysis (Xiao et al., 2000; Zhang et al., 2012). The United States Environmental Protection Agency (US EPA) method 7473 is often adopted for the analysis of mercury (Hg) (Kang et al., 2016). Compared with this complicated method, environmental magnetism can characterize samples with simple processing steps and good sensitivity, and is non-destructive. It has been widely applied in the detection of heavy metal pollutants in dusts (Li et al., 2010), leaves or tree-rings (Zhang et al., 2007), soils (Zhang et al., 2009), and lake sediments (Liu et al., 2006). These studies suggest that rock magnetic parameters are strongly related to the heavy metal concentrations in environmental samples.

Based on ${ }^{210} \mathrm{~Pb}$ dating, continuous lake sediments from the TP can be used to investigate the heavy metal pollution history of lakes over the last hundred years (Yang et al., 2010; Wang et al., 2010). However, the relationship between heavy metals and rock magnetic pa- 
rameters remains poorly understood. It is not clear whether the variation of magnetic minerals in the TP lake sediments is due to environmental changes or human activities since Industrial Revolution. Therefore, we conducted a detailed rock magnetic analysis of Qiangyong Co Lake sediments (southern TP) to investigate the variations in magnetic minerals. The environmental signals were further addressed by assessing the results alongside relevant environmental indexes and the total $\mathrm{Hg}$ concentration of the same sample.

\section{Geological setting, sampling, and experiments}

Qiangyong Co Lake $\left(28.883^{\circ} \mathrm{N}, 90.217^{\circ} \mathrm{E}, \sim 4870\right.$ a.s.1), a proglacial lake of the southern TP, is mainly supplied by glacial meltwater from the Qiangyong Glacier in the summer. There are significant seasonal changes in the hydrologic conditions (Li et al., 2011). In spring and autumn, the lake system is in a relatively stable state, with little meltwater. In summer, a high meltwater discharge enters the lake, and ultimately the lake overflows, forming a river beneath the lake basin. Due to the low temperature in winter, the lake surface is frozen and water loss is mainly due to the sublimation of surface ice. According to meteorological data from Nagarze station ( $\sim 15 \mathrm{~km}$ from Qiangyong Co Lake), the annual mean precipitation and annual average temperature is $\sim 370 \mathrm{~mm}$ and $\sim 2.9^{\circ} \mathrm{C}$, respectively.

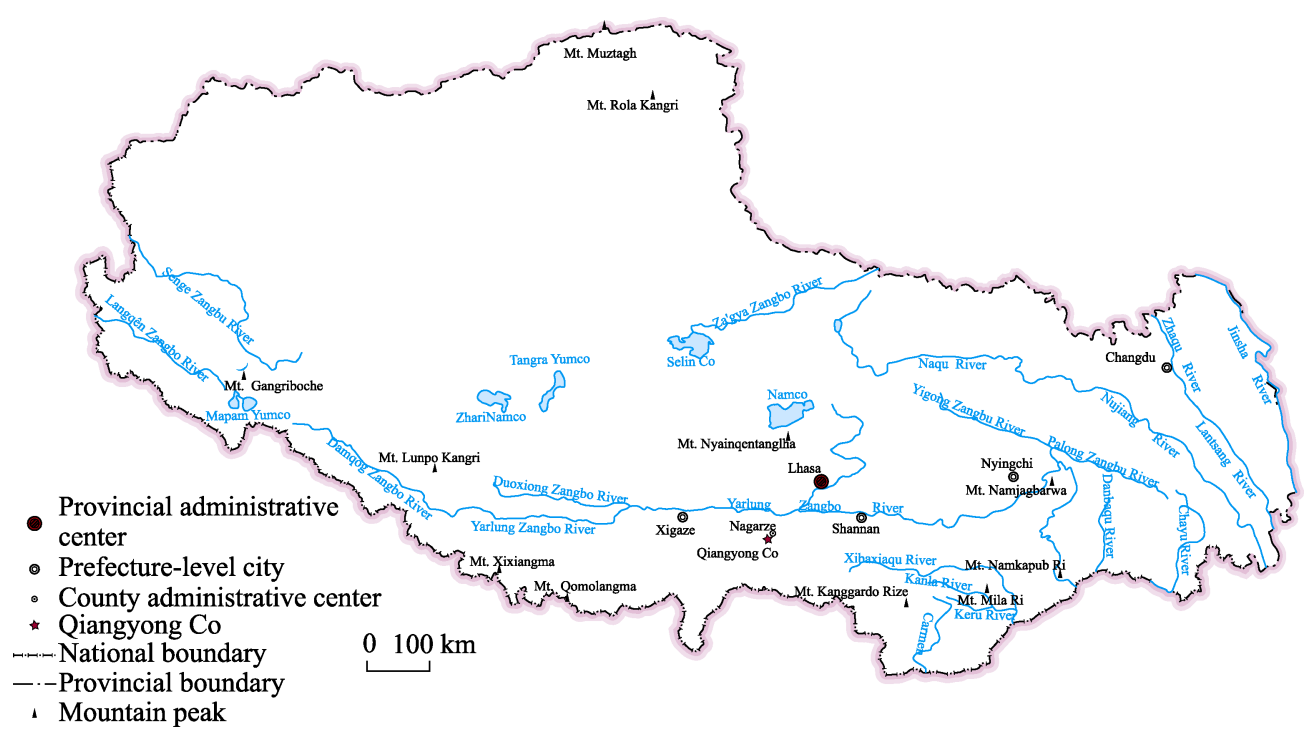

Figure 1 Location of Qiangyong Co Lake

A sediment core was drilled with a gravity corer $(6 \mathrm{~cm}$ in diameter) in 2011 by a scientific expedition team from the Institute of Tibetan Plateau Research, Chinese Academy of Sciences (CAS). In the laboratory, the core was split, and one half was sampled with a stainless-steel knife at $5 \mathrm{~mm}$ intervals. Based on the ${ }^{210} \mathrm{~Pb}$ dating results, the variation of the $\mathrm{Hg}$ concentrations in the top sediment $(0-9.5 \mathrm{~cm})$ reflected the continuous increase in anthropogenic Hg emissions in South Asia from 1899 to 2011 (Kang et al., 2016). This study focused on the same period for which a systematic rock magnetic analysis was conducted. All experiments were performed in the Paleomagnetism and Geochronology Laboratory, 
Institute of Geology and Geophysics, CAS.

After freeze-drying and weighing, samples were placed into cubic plastic boxes $(2.0 \times$ $\left.2.0 \times 2.0 \mathrm{~cm}^{3}\right)$. First, low and high field susceptibility $\left(\chi_{\mathrm{lf}}\right.$ and $\left.\chi_{\mathrm{hf}}\right)$ were measured using an MFK1-Kappabridge magnetic susceptibility meter at frequencies of 976 and $15616 \mathrm{~Hz}$, respectively. Then, anhysteretic remnant magnetization (ARM) was produced and acquired in a $100 \mathrm{mT}$ peak alternating field under a bias field of $0.05 \mathrm{mT}$. Isothermal remnant magnetization (IRM) was acquired in direct current (DC) fields of $1 \mathrm{~T}\left(\mathrm{IRM}_{1 \mathrm{~T}}\right)$ and $-300 \mathrm{mT}$ $\left(\mathrm{IRM}_{-300 \mathrm{mT}}\right.$ ), with a $2 \mathrm{G}$ Enterprise pulse magnetization meter. The $\mathrm{IRM}_{1 \mathrm{~T}}$ was referred to as saturation IRM (SIRM) in this study. Both ARM and IRM were measured with a 2G-760 magnetometer. Magnetic hysteresis loops, IRM curves, and the backfield demagnetization curves were measured in a maximum field of $1 \mathrm{~T}$ using a Model VSM 3900 Magnetometer. Coercivity $\left(B_{c}\right)$, remnant magnetization $\left(M_{r s}\right)$, saturation magnetization $\left(M_{s}\right)$, and the remnant coercivity $\left(\mathrm{B}_{\mathrm{cr}}\right)$ were acquired. The first three parameters were obtained after correction for paramagnetic contribution.

To identify the magnetic assemblage of Qiangyong Co Lake sediments, selected samples were analyzed in a series of experiments. (1) Temperature-dependence magnetic susceptibility $(\chi-\mathrm{T})$ curves were constructed based on measurements in an argon atmosphere using an MFK1-Kappabridge magnetic susceptibility meter from room temperature to $700^{\circ} \mathrm{C}$, with an interval of $5^{\circ} \mathrm{C}$. (2) Zero-field-cooling (ZFC) curves were constructed based on measurements with the MPMS XL-5 magnetic measurement system. After first being cooled to $20 \mathrm{~K}$ in a zero-field, the IRM of samples was acquired in a $2.5 \mathrm{~T}$ field, with measurements made as the temperature was increased from 20 to $300 \mathrm{~K}$ at a rate of $5 \mathrm{~K} / \mathrm{min}$ in a zero-field. (3) First-order reversal curves (FORCs) were measured on a VSM 3900 magnetometer, and FORC diagrams were constructed from 108 FORCs, with a smoothing factor of 7. (4) Diffuse reflectance spectroscopy (DRS) measurements were made from 350 to $2500 \mathrm{~nm}$ using a Varian Cary 5000 spectrophotometer.

\section{Results}

\subsection{Depth plot of variations in rock magnetic proxies}

Based on the ${ }^{210} \mathrm{~Pb}$ chronology results and the variation of the $\mathrm{Hg}$ concentration (Kang et al., 2016), the sequence can be divided into three stages according to the variations of rock magnetic proxies: 1899-1951, 1951-1988, and 1988-2011 (Figure 2).

When evaluating the magnetic content $\chi_{\text {If }}$ is one of the most widely used magnetic properties (Ao and Deng, 2007; Liu et al., 2012). The $\chi_{1 \mathrm{f}}$ of Qiangyong Co Lake ranges between $1.77 \times 10^{-6}-2.43 \times 10^{-6} \mathrm{~m}^{3} / \mathrm{kg}$, with a mean value of $2.05 \times 10^{-6} \mathrm{~m}^{3} / \mathrm{kg}$ (Figure $2 \mathrm{a}$ ). Prior to 1951, $\chi_{\text {lf }}$ displayed an increasing tendency. During the period 1951-1988, $\chi_{\text {lf }}$ changed slightly. After 1988, the $\chi_{\text {lf }}$ value fluctuated. The relative frequency-dependent susceptibility $\left(\chi_{\mathrm{fd}} \%, \chi_{\mathrm{fd}} \%=\left(\chi_{\mathrm{lf}}-\chi_{\mathrm{hf}}\right) / \chi_{\mathrm{lf}} \times 100 \%\right)$ is used to determine the concentration of fine superparamagnetic (SP) and stable single domain (SD) particles (Liu et al., 2012). Except the period 1943-1960, the variation in both $\chi_{\mathrm{lf}}$ and $\chi_{\mathrm{fd}} \%$ displayed a similar tendency. For example, $\chi_{\mathrm{lf}}$ increased suddenly in 1996 corresponding to the peak $\chi_{\mathrm{fd}} \%$ (Figure $2 \mathrm{~b}$ ). This implies the variation of $\chi_{\mathrm{lf}}$ is related to the finer magnetic particle content. 
(a)

(b)

(c)

(d)

(e)

(f)

(g)

(h)

(i)

$\chi_{\text {ff }}\left(10^{-6} \mathrm{~m}^{3} / \mathrm{kg}\right) \quad \chi_{\mathrm{fo}} \% \quad \operatorname{ARM}\left(10^{-5} \mathrm{Am}^{2} / \mathrm{kg}\right) \quad \operatorname{SIRM}\left(\mathrm{Am}^{2} / \mathrm{kg}\right) \quad \mathrm{S}_{0.3} \quad \operatorname{ARM} / \operatorname{SIRM}\left(10^{-5}\right) \quad \operatorname{ARM} / \chi_{\mathrm{ff}}(\mathrm{A} / \mathrm{m}) \quad \mathrm{SIRM} / \chi_{\mathrm{fr}}(\mathrm{A} / \mathrm{m}) \quad \mathrm{Hg}(\mathrm{ng} / \mathrm{g})$

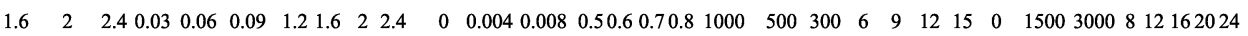

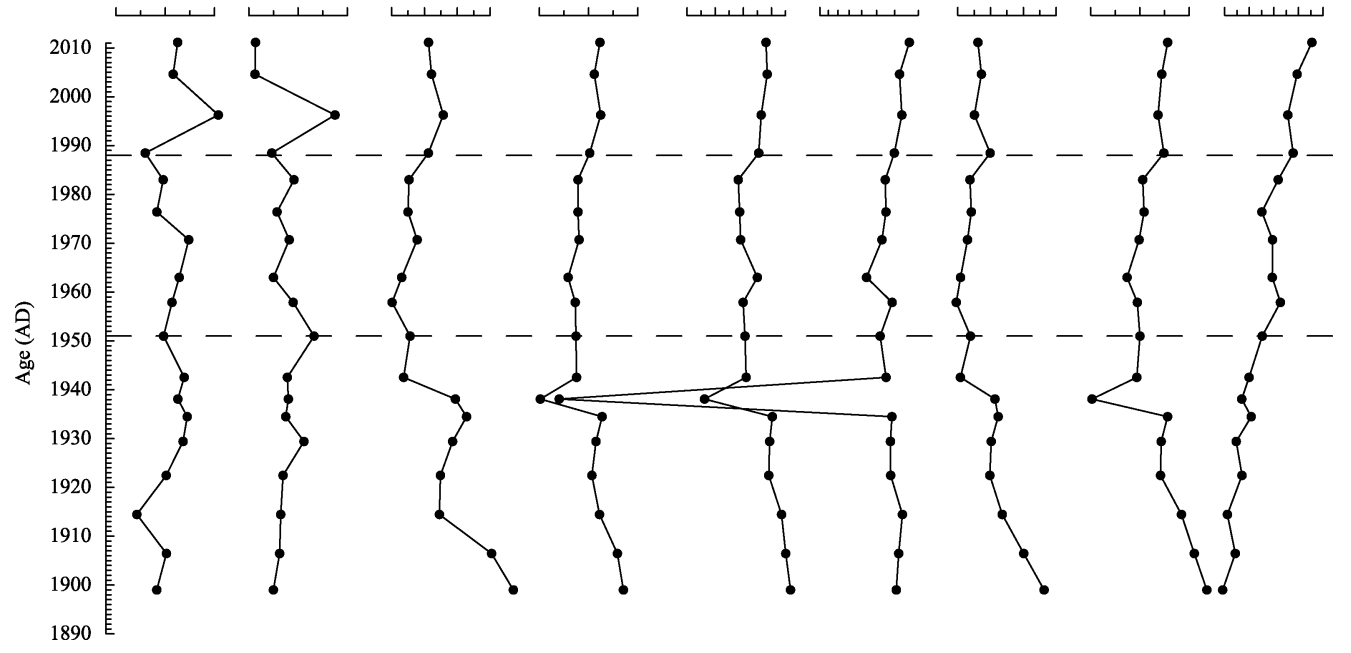

Figure 2 Environmental magnetic parameters and mercury $(\mathrm{Hg})$ concentrations of Qiangyong Co Lake (the $\mathrm{Hg}$ concentration and Qiangyong chronology are from Kang et al., 2016)

ARM is mainly related to the SD particle content (Duan et al., 2012). The ARM of Qiangyong Co Lake was between $1.21 \times 10^{-5}-2.68 \times 10^{-5} \mathrm{Am}^{2} / \mathrm{kg}$ and displayed a pattern of variation that differed from that of $\chi_{\mathrm{lf}}$ (and $\chi_{\mathrm{fd}} \%$ ). There was a tendency for ARM to decrease from 1899 to 1951, followed by a slight increase until 1988, and then a decline during 1988-2011 (Figure 2c). Another concentration related magnetic parameter, SIRM, displayed a similar tendency to that of ARM aside from 1938 (Figure 2d).

The S-ratio $\left(\mathrm{S}_{0.3}, \mathrm{~S}_{0.3}=\mathrm{IRM}_{-300 \mathrm{mT}} / \mathrm{SIRM}\right)$ is commonly used to determine the relative contribution of "soft" magnetic minerals (e.g., magnetite) compared to "hard" magnetic minerals (e.g., hematite and goethite) (Liu et al., 2012). The mean value of $\mathrm{S}_{0.3}$ was 0.751 , which suggested that the dominant magnetic minerals are "soft", e.g., magnetite. The overall changes of $\mathrm{S}_{0.3}$ were similar to those of SIRM (Figure 2e). The variation of the magnetic mineral content in Qiangyong Co Lake sediments was therefore dominated by soft magnetic minerals (e.g., magnetite).

The grain size dependent parameters ARM/SIRM, ARM/ $\chi_{\text {lf }}$ and $\mathrm{SIRM} / \chi_{\text {lf }}$ exhibited significant variations (Figures $2 \mathrm{f}-2 \mathrm{~h}$ ). Both $\mathrm{ARM} / \chi_{\text {lf }}$ and $\mathrm{SIRM} / \chi_{\text {lf }}$ tended to decrease from 1899 to 1951 , implying the reduction of finer magnetic particles, but ARM/SIRM changed only slightly. During the period 1951-1988, all grain size dependent parameters varied slightly. Since 1988, both ARM/SIRM and SIRM/ $\chi_{\text {If }}$ had a tendency to increase, implying an increase in the amount of finer magnetic particles. The overall pattern of variation among the three parameters was similar, but not completely equivalent at the different stages. In comparison, $\mathrm{SIRM} / \chi_{\text {lf }}$ was more suitable for representing the variation of magnetic grain size.

\subsection{Magnetic assemblage}

Day-plot diagrams of the $\mathrm{M}_{\mathrm{rs}} / \mathrm{M}_{\mathrm{s}}$ and $\mathrm{B}_{\mathrm{cr}} / \mathrm{B}_{\mathrm{cr}}$ values are widely used to visualize the domain state of the ferromagnetic minerals (Day et al., 1977; Dunlop, 2002a, 2002b). The Day-plots of Qiangyong Co Lake sediments are generally approaching to the SD region (Figure 3a). The 1899-1951 and 1988-2011 samples were mainly located in the top left corner close to the SD 
region, but the samples of 1951-1988 were generally plotted on the pseudo-single domain (PSD) region. It has been reported that the plotted values will shift to the top-right region when there is a certain amount of hematite (Dunlop, 2002a; Chen et al., 2009).
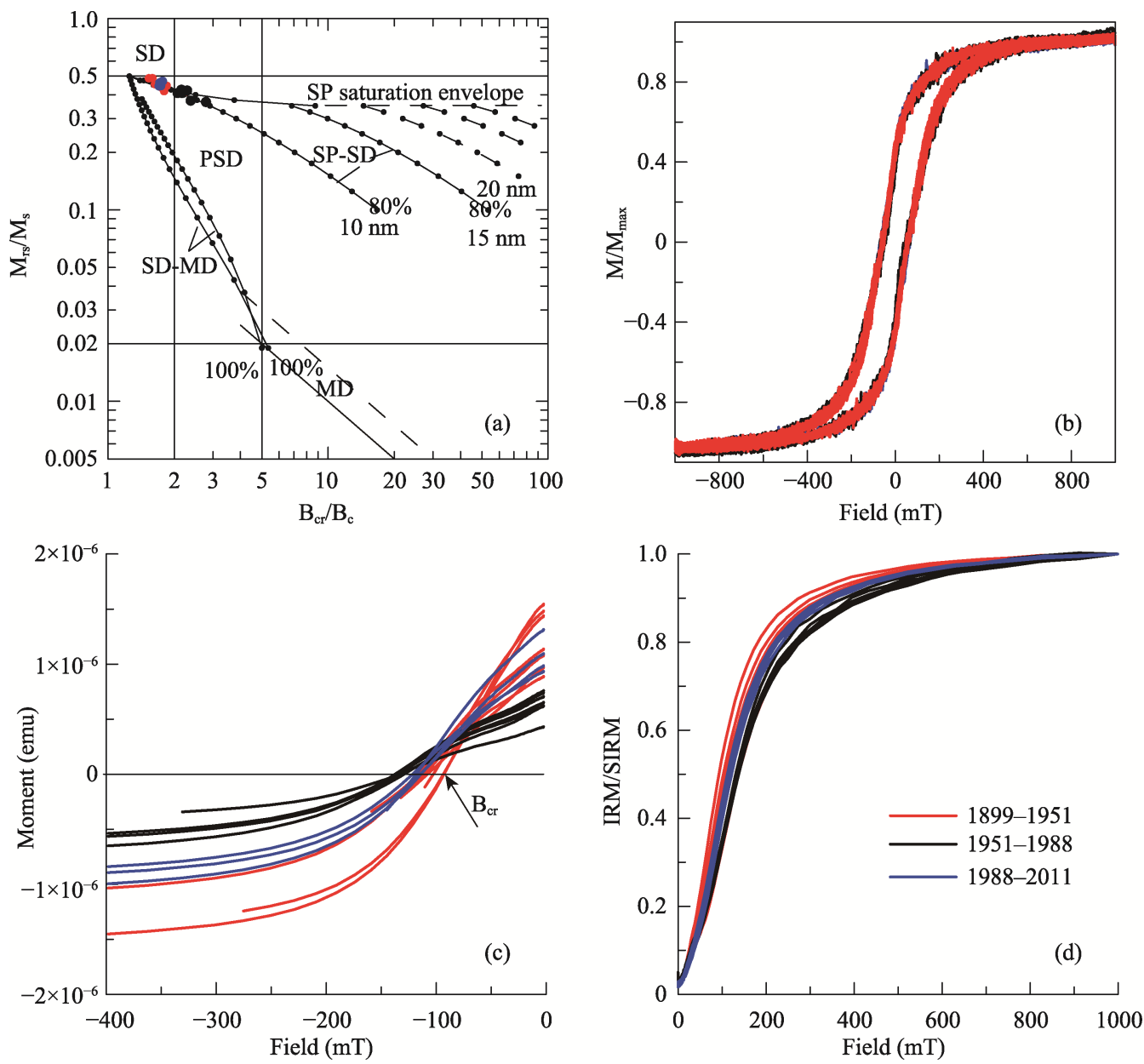

Figure 3 Day-plot (a), magnetic hysteresis loops (b), isothermal remnant magnetization (IRM) acquisition curves (c), and backfield demagnetization curves (d) of Qiangyong Co Lake

Characterized by a wasp-waisted hysteresis, the loops displayed a similar behavior from 1899 to 2011 that did not close until $800 \mathrm{mT}$ (Figure 3b), which indicated the coexistence of magnetic minerals with contrasting coercivities (Roberts et al., 1995). The IRM curves and backfield demagnetization curves are shown in Figures 3c-3d. Overall, the IRM curves rose sharply before $300 \mathrm{mT}$, then slowly increased to almost saturation at $600 \mathrm{mT}$, although the "hard" magnetic minerals were not completely saturated even at $1 \mathrm{~T}$. This phenomenon was consistent with the hysteresis loop results. The $\mathrm{B}_{\mathrm{cr}}$ value and the behavior of the IRM was also correlated (Figures 2c-2d). Among the three periods investigated, 1899-1951 had the smallest mean $\mathrm{B}_{\mathrm{cr}}$ value $(103.09 \mathrm{mT})$ and the most rapid rise in the IRM curves of the samples occurred before $300 \mathrm{mT}$. During 1988-2011, the slowest rise in the IRM curves for the samples with the largest mean value of $B_{c r}(132.26 \mathrm{mT})$ occurred before $300 \mathrm{mT}$. During 1951-1988, the samples had a median $B_{\mathrm{cr}}$ value that corresponded to an intermediate rate of increase in the IRM curves. 
A FORC diagram is very useful for identifying the domain state of magnetic materials and the interaction field among magnetic particles (Liu et al., 2012). Characteristic samples of the three stages displayed a similar shape (Figures $4 \mathrm{~b}-4 \mathrm{~d}$ ), with a distinct component around $\sim 20 \mathrm{mT}$ and a large spread along the $\mathrm{H}_{\mathrm{c}}$ axis, which suggested that the sample had a complex magnetic mineral composition. To determine the magnetic composition of samples, IRM curves were unmixed using the method adopted by Heslop et al. (2002) and Egli (2003). All samples consisted of four components: Component 1 (C1, $\mathrm{B}_{1 / 2}$ : 112 mT), Component 2 (C2, B $\left.{ }_{1 / 2}: 186.2-330 \mathrm{mT}\right)$, Component $3\left(\mathrm{C} 3, \mathrm{~B}_{1 / 2}: 36.3 \mathrm{mT}\right)$, and Component $4\left(\mathrm{C} 4, \mathrm{~B}_{1 / 2}: 6.3 \mathrm{mT}\right.$ ) (Figures $4 \mathrm{e}-4 \mathrm{j}$ ). $\mathrm{C} 3$ and $\mathrm{C} 4$ corresponded to low coercivity ( "soft" ) minerals (e.g., magnetite and maghemite). Both contributed to the closed concentric contours about a central peak of $\sim 20 \mathrm{mT}$ for $\mathrm{H}_{\mathrm{c}}$. $\mathrm{C} 1$ and $\mathrm{C} 2$ corresponded to median and high coercivity minerals, respectively (e.g., hematite and goethite), which are the magnetic carriers for the broad spread of $\mathrm{H}_{\mathrm{c}}$.
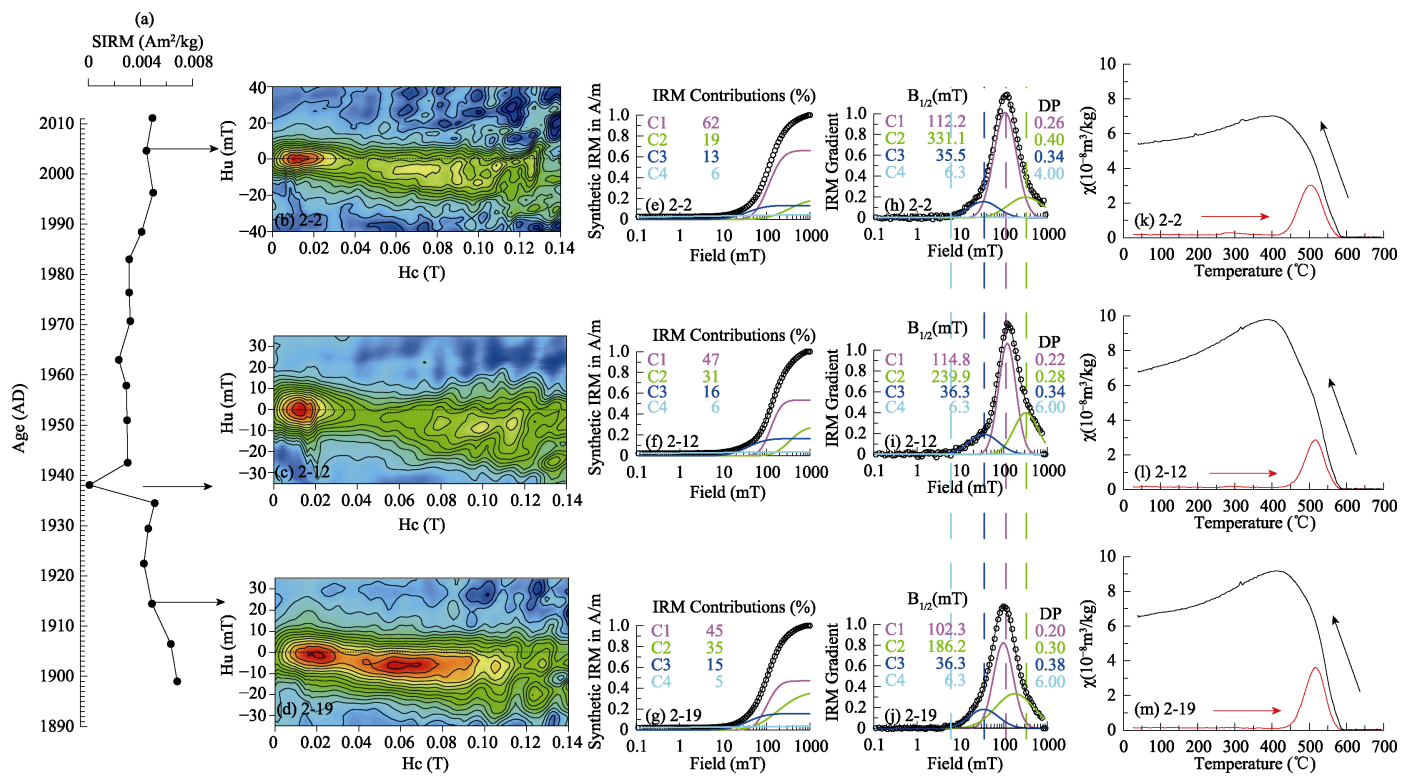

Figure 4 Saturation isothermal remnant magnetization (SIRM) (a), Unmixing of IRM acquisition curves (b-g), First-order reversal curves (FORCs) $(\mathrm{h}-\mathrm{j})$ and $\chi-\mathrm{T}(\mathrm{k}-\mathrm{m})$ of typical samples

The characters of the $\chi$-T curves for selected samples were similar (Figures $4 \mathrm{k}-4 \mathrm{~m}$ ). The heating curves of $\chi$-T exhibited a weak increase between $\sim 250$ and $300^{\circ} \mathrm{C}$, which was probably related to the neoformation of maghemite (Deng et al., 2002). Up to $\sim 430^{\circ} \mathrm{C}, \chi$ increased rapidly and then displayed a notable peak around $\sim 520^{\circ} \mathrm{C}$. This phenomenon resembled the $\chi$-T curves for the Quaternary loess (Deng et al., 2002). There are two possible mechanisms for the phenomenon: the Hopkinson effect of SD particles and the neoformation of magnetite. During the heating cycle, $\chi$-T exhibited a marked decrease at $\sim 585^{\circ} \mathrm{C}$, but with a tail until $700^{\circ} \mathrm{C}$, which indicated the presence of hematite. The cooling and heating curves were reversible between $\sim 510$ and $\sim 700^{\circ} \mathrm{C}$, which indicated the presence of SD particles, with the Hopkinson effect. The $\chi$ values after the cooling process were higher than those of the samples before the heating process, which indicated the generation of some strongly magnetic minerals (e.g., magnetite) during the heating process. 
No Verwey transition was found in the raw data of the ZFC curves, but it was found in the first-order derivative data of the ZFC curves (Figure 5a), implying there was some magnetite in the SP particles or some undetectable multi-domain magnetite (Verwey, 1939; Muxworthy and McClelland, 2000; Kosterov, 2003). In the second-derivative curves of the DRS data, hematite and goethite were conformed to have notable wave troughs at $\sim 535$ and $\sim 25 \mathrm{~nm}$, respectively (Torrent and Barrón, 2008; Jiang et al., 2016). The presence of goethite and hematite was therefore indicated from the second-derivative curves of DRS data of selected samples (Figure 5b).
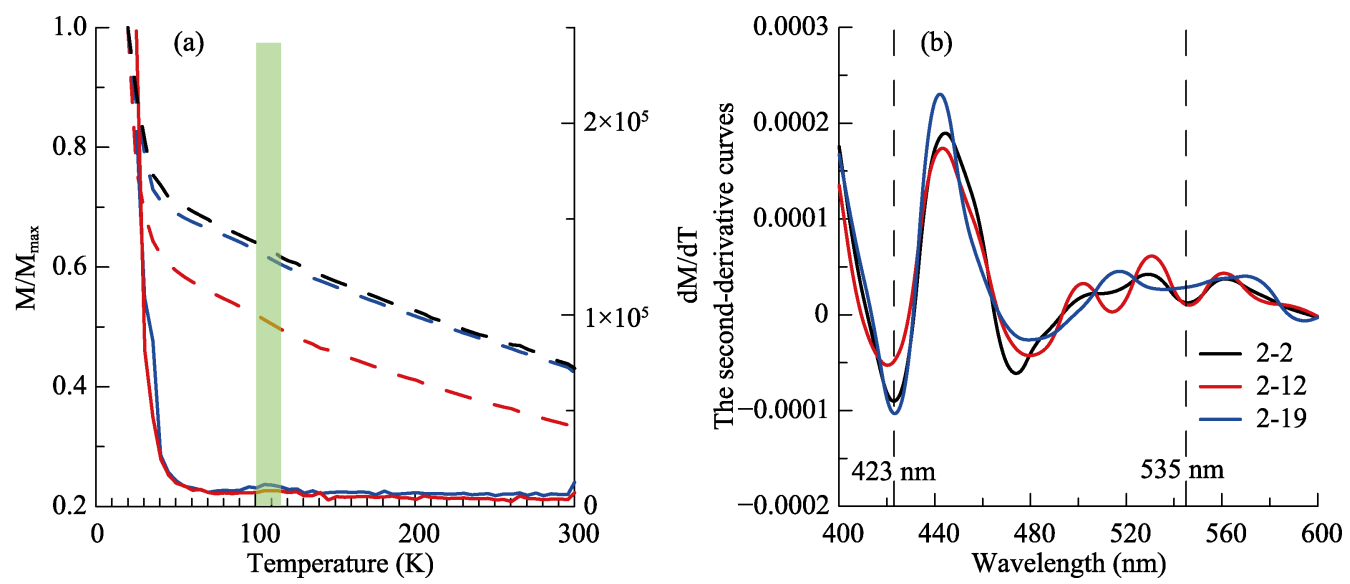

Figure 5 Zero-field-cooling (ZFC) curves (a, the solid and dashed lines represent the origin data and first derivative data of the ZRC curves, respectively) and the second derivative curves of diffuse reflectance spectroscopy (DRS) (b) for selected samples from Qiangyong Co Lake

Combined with the results of all experiments, the magnetic minerals of Qiangyong Co Lake sediments are contributed by four components from 1899 to 2011, implying the sources of magnetic minerals for the Qiangyong Lake sediments have not changed since 1899. From the FORC diagrams, $\chi-T, Z F C$ curves, and DRS data, it was possible to identify C3 and C4 as magnetite, C2 as goethite, and C1 as finer hematite based on the Day-plot analysis. This kind of hematite has also been found in paleosols (Hu et al., 2013).

\section{Discussion}

Both $\chi_{\text {If }}$ and SIRM can be used as proxy indicators for heavy metals. For example, $\chi_{\text {lf }}$ was found to correlate strongly with the $\mathrm{Hg}$ concentration in samples from Baiyangdian Lake, northern China (Guo et al., 2015). For Qiangyong Co Lake sediment samples, the relationship between SIRM (or $\chi_{\text {lf }}$ ) and the Hg concentration is complicated (Figures $2 \mathrm{a}, 2 \mathrm{~d}$, and 2i). Before 1951, there was a positive correlation between $\chi_{1 f}$ and the $\mathrm{Hg}$ concentration (Figure 6a), but a negative correlation between SIRM (or SIRM/ $\chi_{\mathrm{lf}}$ ) and the $\mathrm{Hg}$ concentration (Figures $6 \mathrm{~b}-6 \mathrm{c})$. However, after 1951, there was no obvious relationship between $\chi_{\mathrm{lf}}$ and the $\mathrm{Hg}$ concentration (Figure $6 \mathrm{a}$ ), but there was a positive correlation between SIRM (or SIRM/ $\chi_{\mathrm{lf}}$ ) and the $\mathrm{Hg}$ concentration (Figures $6 \mathrm{~b}-6 \mathrm{c}$ ). This phenomenon was likely due to the different controlling factors. There were some SP particles which contributed to the high $\chi_{1 \mathrm{f}}$, but did not contribute to the SIRM. The magnetic minerals of Qiangyong Co Lake consisted of four different components. They therefore differed from the Baiyangdian Lake sediment, which 
were found to be dominated by ferrimagnetic minerals generated by industrial activities (Guo et al., 2015). Additionally, the proportion of the four components varied to different extents from 1899 to 2011, with a few exceptions (the years 1922 and 1971). The percentage content of $\mathrm{C} 1$ continuously increased, the percentage content of $\mathrm{C} 2$ continually decreased, the percentage content of $\mathrm{C} 3$ fluctuated between $11 \%$ and $16 \%$, and the percentage content of $\mathrm{C} 4$ remained relatively constant at $\sim 6 \%$. The changing proportions of the different components would have different effects on SIRM and $\chi_{\mathrm{lf}}$. Therefore, the variation of the $\mathrm{Hg}$ concentration cannot be simply expressed by $\chi_{\text {If }}$ or SIRM for Qiangyong Co Lake sediments.
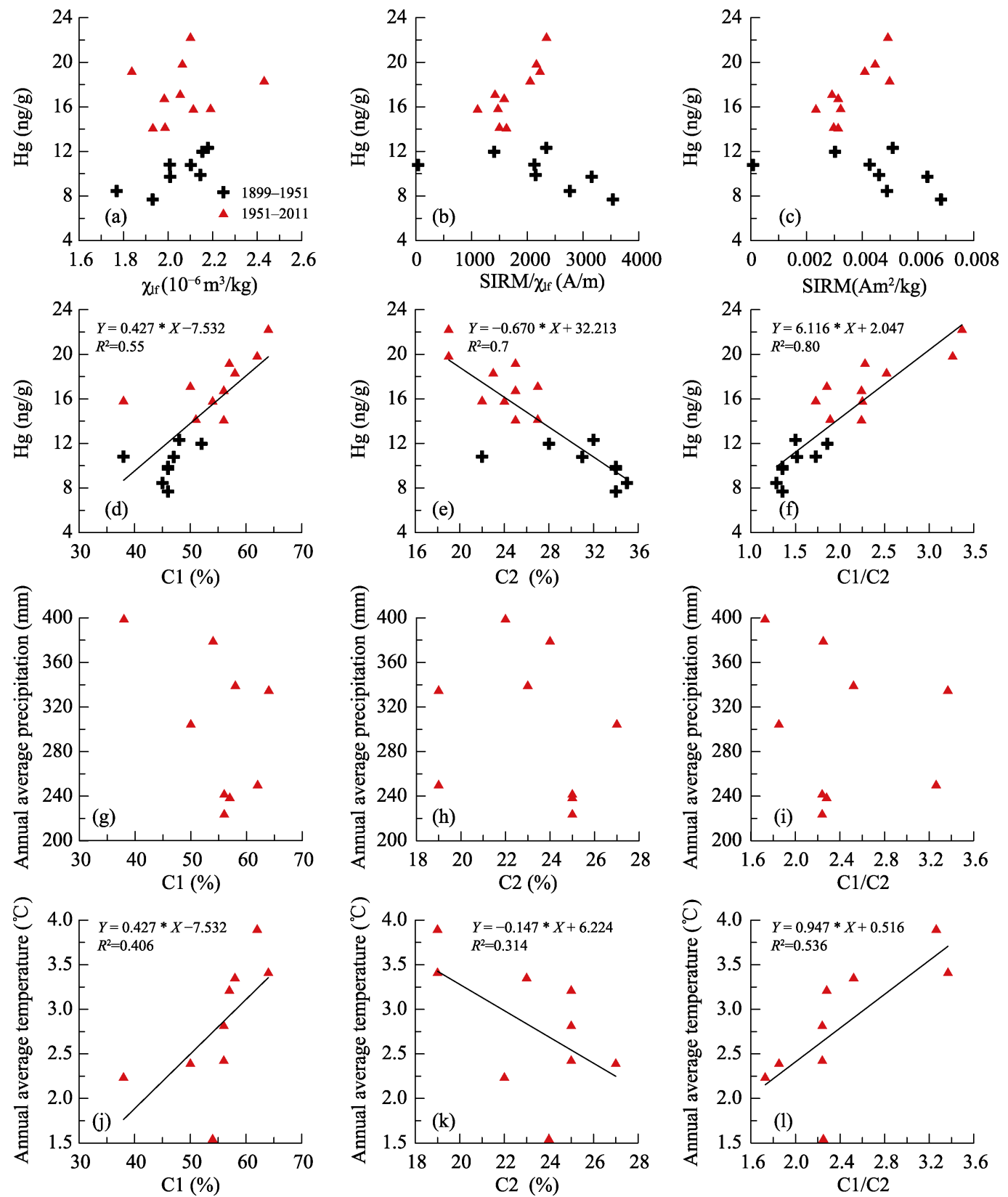

Figure 6 Correlations between the variations of magnetic components and mercury $(\mathrm{Hg})$ concentration in Qiangyong Co Lake and environmental indexes (annual average precipitation and temperature) of Nagarze station 
In Qiangyong Co Lake, the proportions of C3 and C4 changed slightly, which was related to the increased $\mathrm{Hg}$ content. However, there was a strong positive (or negative) relationship between the proportion of $\mathrm{C} 1$ (or $\mathrm{C} 2$ ) and the $\mathrm{Hg}$ concentration (Figures 6d-6e, 7a-7b and $7 \mathrm{~h}$ ), with the exception of 1922 and 1971. A closer relationship was found between the ratio of $\mathrm{C} 1$ to $\mathrm{C} 2(\mathrm{C} 1 / \mathrm{C} 2)$ and the $\mathrm{Hg}$ concentration (Figure $6 \mathrm{f})$. Previous studies have shown that there are two possible mechanisms that explain the positive correlation between magnetic parameters and heavy metals. One is that both the magnetic minerals and heavy metal minerals are generated together by industrial combustion or heating processes (Hanech et al., 2003; Hu et al., 2008). The other is that magnetic minerals with a large surface area can absorb heavy metals (e.g., $\mathrm{Pb}$ and $\mathrm{Hg}$ ), and they go through the same process of transport and precipitation (Gautam et al., 2005; Spiteri et al., 2005). Magnetic minerals (magnetite, hematite, and pyrrhotite) produced by industrial processes are larger than naturally occurring magnetic minerals (e.g., Zhang et al., 2009). In Qiangyong Co Lake sediments, magnetic minerals were primarily composed of finer particles as revealed by the Day plot (Figure 3a), which was not consistent with the reported industrially-generated magnetic minerals. The transport of magnetic minerals by dust and aerosol follows a clear distance-decay law, with smaller quantities transported further distances. Qiangyong Co Lake is located in the southern TP, a developing area of industrialization far human pollution sources. The magnetic mineral species have clearly not changed since 1899 . Thus, industrial pollution can therefore be excluded as the major source of the magnetic minerals of the Qiangyong Co Lake sediments.

The pathways by which $\mathrm{Hg}$ and magnetic minerals entered Qiangyong Co Lake were similar. $\mathrm{Hg}$ enters the lake system by dry or wet deposition, while magnetic minerals are transported to the lake system by dust, rainfall, and runoff. The most likely mechanism for the strong positive correlation between the $\mathrm{Hg}$ content and the proportion of $\mathrm{C} 1$ is that hematite, with a large surface area, can absorb $\mathrm{Hg}$ and both will then settle into Qiangyong Co Lake via the same transport process. In contrast, C2 avoids $\mathrm{Hg}$ adsorption and its proportional content declined with the increase in $\mathrm{C} 1$ content since 1899 . This could explain the strong negative correlation between $\mathrm{Hg}$ and $\mathrm{C} 2$, and why there was significant stronger linear relationship between the $\mathrm{Hg}$ concentration and $\mathrm{C} 1 / \mathrm{C} 2$.

The main water sources for Qiangyong Co Lake are glaciers and snow meltwater rivers on Qiangyong Glacier. Glacier and snow runoff are therefore the main carriers of magnetic minerals into Qiangyong Co Lake. Of the four components, C1 (hematite) accounted for the largest percentage since 1899. Therefore, C1 should correspond to the magnetic minerals transported by glacier and snow runoff. The annual average temperature of both Nagarze station and the whole TP displayed a warming tendency from 1951 to 2011 (Duan et al., 2011). The Northern Hemisphere temperature anomaly has continually increased since 1899 . Local and global warming has resulted in the rapid melting of glaciers and large amounts of $\mathrm{C} 1$ are carried by the increased meltwater volume. This was verified by the strong correspondence between the magnetic components and annual average temperature of Nagarze station from 1951 to 2011 (Figures $6 \mathrm{j}-61$ and $7 \mathrm{f}-7 \mathrm{~h}$ ). Glaciers are a temporary reservoir of $\mathrm{Hg}$ (Zhang et al., 2012), which is released again with glacier or snow melt. Cong et al. (2018) found that magnetic minerals (hematite and goethite) are important constituents of cryoconite, which is a mixture of incoherent impurities and ice that is present on the surface of gla- 
ciers in summer. Through the enrichment and release processes, $\mathrm{Hg}$ is absorbed by hematite and ultimately transported to Qiangyong Co Lake.

Unstable local atmospheric circulations can induce dust storms when the temperature increases (Hu and Mistuta, 1997). Duan et al. (2011) found that the occurrence of dust storms peaked around the 1980s. This pattern differed from the variations of $\mathrm{Cl}$ and the $\mathrm{Hg}$ concentration. Dry deposition related to dust activities was not the main source of $\mathrm{Cl}$ and $\mathrm{Hg}$. It may also be possible that $\mathrm{Hg}$ and magnetic minerals enter Qiangyong Co Lake by precipitation. There has been a trend for $\mathrm{Hg}$ levels in precipitation to increase in connection with the recent economic development in South Asia in the southern TP (Huang et al., 2015). The annual average precipitation of Nagarze station has fluctuated frequently since 1951, with no direct relationship with $\mathrm{C} 1$ (Figures $6 \mathrm{~g}-6 \mathrm{i}, 7 \mathrm{e}$ and $7 \mathrm{~h}$ ). We can therefore rule out the possibility that the hematite in Qiangyong Co Lake originated mainly from rainfall, with few insoluble particles present in precipitation. However, some proportion of the $\mathrm{Hg}$ will originate from rainfall. This explains why the relationship between the $\mathrm{Hg}$ concentration and $\mathrm{C} 1$ was not strongly correlated.

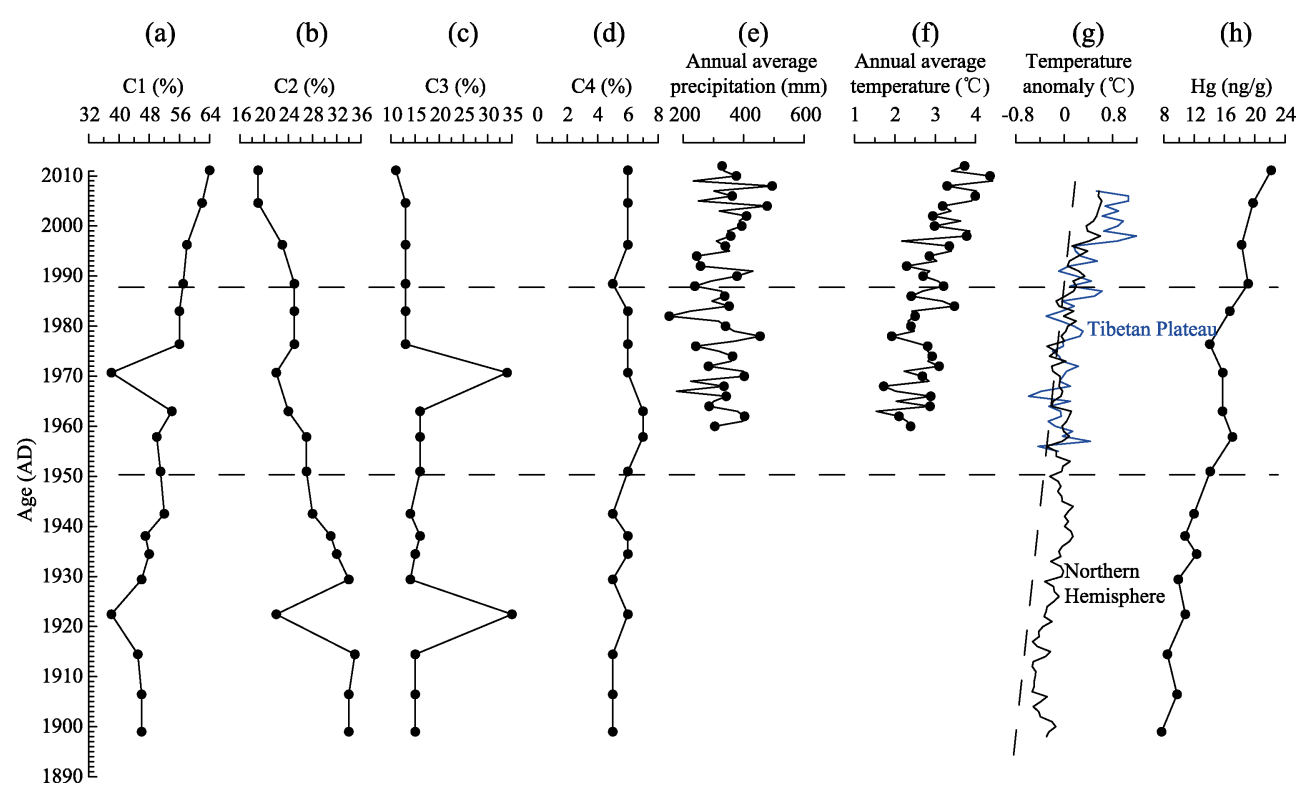

Figure 7 The variations of different magnetic components of Qiangyong Co Lake (a-d), annual precipitation (e), average temperature from Nagarze station (f), temperature anomaly of the Tibetan Plateau and the Northern Hemisphere (g), and $\mathrm{Hg}$ concentration (h) (the Hg concentration and Qiangyong chronology are from Kang et al., 2016; the temperature anomaly of the Tibetan Plateau and the Northern Hemisphere)

\section{Conclusion}

The magnetic mineral species in Qiangyong Co Lake sediments did not change from 1899 to 2011, and were composed of four components: C1 (hematite), C2 (goethite), and C3 and C4 (magnetite). The percentage content of each component varied, with the proportion of $\mathrm{C} 3$ and $\mathrm{C} 4$ changing slightly, the proportion of $\mathrm{C} 1$ increasing, and the proportion of $\mathrm{C} 2$ decreasing. Therefore, SIRM and $\chi_{\mathrm{lf}}$ were unsuitable for evaluating the $\mathrm{Hg}$ concentration. There was a strong positive correlation between the proportion of $\mathrm{C} 1$ and the $\mathrm{Hg}$ concentra- 
tion. The proportion of hematite can therefore be used as a semi-quantitative proxy to evaluate the $\mathrm{Hg}$ content for Qiangyong Co Lake sediments. The most likely mechanism is that a large amount of $\mathrm{Hg}$ that had deposited and was sealed on the Qiangyong Glacier was released again with the rapid melting of the glacier as the climate has warmed since 1899. In this process, hematite with a large surface area absorbed $\mathrm{Hg}$, which was then transported to Qiangyong Co Lake by glacier meltwater.

This study confirmed that magnetic parameters (i.e., the proportion of hematite) can be used to evaluate the variation of heavy metal $(\mathrm{Hg})$ concentrations in the TP lakes. Such evaluations should be conducted with detailed and careful environmental magnetic experiments. Future studies will be conducted on the other proglacial lakes of the southern TP, and then extended to the whole TP to confirm our findings. A determination of the hematite and $\mathrm{Hg}$ transport processes is vital, and therefore cryoconite and Qiangyong glacier meltwater, surface soils around Qiangyong Co Lake and runoff area, local rainfall, and dust will be sampled to conduct magnetic and $\mathrm{Hg}$ analyses.

\section{References}

Ao Hong, Deng Chenglong, 2007. Review in the identification of magnetic minerals. Progress in Geophysics, 22(2): 432-442. (in Chinese)

Chen P F, Kang S C, Li C L et al., 2019. Carbonaceous aerosol characteristics on the Third Pole: A primary study based on the Atmospheric Pollution and Cryospheric Change (APCC) network. Environmental Pollution, 253: 49-60.

Chen Xi, Zhang Weiguo, Yu Lizhong, 2009. The dependence of magnetic parameters on the mixing proportion of hematite and magnetite. Progress in Geophysics, 24(1): 82-88. (in Chinese)

Cong Zhiyuan, Gao Shaopeng, Zhao Wancang et al., 2018. Iron oxides in the cryoconite of glaciers on the Tibetan Plateau: Abundance, speciation and implications. Cryosphere Discussions, 12: 3177-3186.

Cong Zhiyuan, Kang Shichang, Zheng Wei et al., 2010. Modern process and historical reconstruction of $\mathrm{Pb}$ and $\mathrm{Hg}$ in remote areas: A critical review. Acta Geographica Sinica, 65(3): 351-360. (in Chinese)

Day R, Fuller M, Schmidt V A, 1977. Hysteresis properties of titanomagnetites: Grain size and compositional dependence. Physics of the Earth and Planetary Interiors, 13(4): 260-267.

Deng Chenglong, Zhu Rixiang, Yuan Baoyin, 2002. Rock magnetism of the Holocene eolian in the Loess Plateau: Evidence for pedogenesis. Marine Geology \& Quaternary Geology, 11(2): 37-45. (in Chinese)

Duan Zongqi, Gao Xing, Liu Qingsong et al., 2011. Magnetic characteristics of insoluble microparticles in ice core (Nojingkangsang) from the southern Tibetan Plateau and its environmental significance. Science China Earth Sciences, 54(11): 1635-1642.

Duan Zongqi, Gao Xing, Liu Qingsong, 2012. Anhysteretic remanent magnetization (ARM) and its application to geoscience. Progress in Geophysics, 27(5): 1929-1938. (in Chinese)

Dunlop D J, 2002a. Theory and application of the Day plot $\left(\mathrm{M}_{\mathrm{rs}} / \mathrm{M}_{\mathrm{s}}\right.$ versus $\left.\mathrm{H}_{\mathrm{cr}} / \mathrm{H}_{\mathrm{c}}\right)$ 1. Theoretical curves and tests using titanomagnetite data. Journal of Geophysical Research, 107(B3): EPM1-EPM4-22.

Dunlop D J, 2002b. Theory and application of the Day plot $\left(\mathrm{M}_{\mathrm{rs}} / \mathrm{M}_{\mathrm{s}}\right.$ versus $\left.\mathrm{H}_{\mathrm{cr}} / \mathrm{H}_{\mathrm{c}}\right)$ 2. Application to data for rocks, sediments, and soils. Journal of Geophysical Research, 107(B3): EPM1-EPM5-15.

Egli R, 2003. Analysis of the field dependence of remanent magnetization curves. Journal of Geophysical Research, 108: B2, doi: 10.1029/2002JB002023.

Gautam P, Blaha U, Appel E, 2005. Magnetic susceptibility of dust-loaded leaves as a proxy of traffic-related heavy metal pollution in Kathmandu city, Nepal. Atmospheric Environment, 39(12): 2201-2211.

Guo Bixi, Liu Yongqin, Zhang Fan et al., 2016. Characteristics and risk assessment of heavy metals in core sediments from lakes of Tibet. Environmental Science, 37(2): 490-498. (in Chinese)

Guo Chao, Meng Hongwei, Ma Yuzhen et al., 2019. Environmental variations recorded by chemical element in 
the sediments of Lake Yamzhog Yumco on the southern Tibetan Plateau over the past 2000 years. Acta Geographica Sinica, 74(7): 1345-1362. (in Chinese)

Guo Wei, Huo Shouliang, Ding Wenjuan, 2015. Historical record of human impact in a lake of northern China: Magnetic susceptibility, nutrients, heavy metals and OCPs. Ecological Indicators, 57: 74-81.

Hanesch M, Scholger R, Rey D, 2003. Mapping dust distribution around an industrial site by measuring magnetic parameters of tree leaves. Atmospheric Environment, 37(36): 5125-5133.

Heslop D, Dekkers M J, Kruiver P P et al., 2002. Analysis of isothermal remanent magnetization acquisition curves using the expectation-maximization algorithm. Geophysical Journal International, 148(1): 58-64.

$\mathrm{Hu}$ P, Liu Q, José Torrent et al., 2013. Characterizing and quantifying iron oxides in Chinese loess/paleosols: Implications for pedogenesis. Earth and Planetary Science Letters, 369/370(3): 271-283.

Hu Shouyun, Duan Xuemei, Shen Mingjie et al., 2008. Magnetic response to atmospheric heavy metal pollution recorded by dust-loaded leaves in Shougang industrial area, Western Beijing. Chinese Science Bulletin, 53(10): 1555-1564. (in Chinese)

Hu Y Q, Mitsuta Y, 1997. Micrometeorological characteristics and local triggering mechanism of strong dust storm. Scientia Atmospherica Sinica, 21: 581-589. (in Chinese)

Huang Jie, Kang Shichang, Ma Ming et al., 2019. Accumulation of atmospheric mercury in glacier cryoconite over western China. Environmental Science \& Technology, 53(13): 6632-6639.

Huang Jie, Kang Shichang, Zhang Qianggong et al., 2015. Characterizations of wet mercury deposition on a remote high-elevation site in the southeastern Tibetan Plateau. Environmental Pollution, 206: 518-526.

Jiang Zhaoxia, Liu Qingsong, 2016. Quantification of hematite and its climatic significances. Quaternary Sciences, 36(3): 676-689. (in Chinese)

Kang S C, Huang J, Wang F Y et al., 2016. Atmospheric mercury depositional chronology reconstructed from lake sediments and ice core in the Himalayas and Tibetan Plateau. Environmental Science \& Technology, 50(6): 2859-2869.

Kang S C, Zhang Q G, Qian Y et al., 2019. Linking atmospheric pollution to cryospheric change in the Third Pole region: Current progress and future prospects. National Science Review, 6(4): 796-809.

Kosterov A, 2003. Low-temperature magnetization and AC susceptibility of magnetite: Effect of thermomagnetic history. Geophysical Journal International, 154: 58-71.

Li C, Bosch C, Kang S et al., 2016. Sources of black carbon to the Himalayan-Tibetan Plateau glaciers. Nature Communications, 7: 12574, doi: 10.1038/nomms12574.

Li Chaoliu, Kang Shichang, Cong Zhiyuan, 2007. Elemental composition of aerosols collected in the glacier area on Nyainqêntanglha Range, Tibetan Plateau, during summer monsoon season. Chinese Science Bulletin, 52(24): 3436-3442.

Li Jiule, Xu Baiqing, Lin Shubiao et al., 2011. Glacier and climate changes over the past millennium recorded by proglacial sediment sequence from Qiangyong Lake, Southern Tibetan Plateau. Journal of Earth Sciences and Environment, 33(4): 402-411. (in Chinese)

Li Peng, Qiang Xiaoke, Tang Yanrong et al., 2010. Magnetic susceptibility of the dust of street in Xi'an and the implication on pollution. China Environmental Science, 30(3): 309-314. (in Chinese)

Liu Q, Roberts A P, Larrasoaña J C et al., 2012. Environmental magnetism: Principles and applications. Reviews of Geophysics, 50(4): RG4002, doi:10.1029/2012RG000393.

Liu Yang, Ma Zongwei, Lv Jianshu et al., 2016. Identifying sources and hazardous risks of heavy metals in topsoils of rapidly urbanizing East China. Journal of Geographical Sciences, 26(6): 735-749.

Liu Zhendong, Liu Qingsheng, Wan Hansheng et al., 2006. Relationship between magnetic properties and heavy metals of sediments in Donghu Lake, Wuhan, China. Earth Science-Journal of China University of Geosciences, 31(2): 266-272. (in Chinese)

Mamattursun Eziz, Ajigul Mamut, Anwar Mohammad et al., 2017. Assessment of heavy metal pollution and its potential ecological risks of farmland soils of oasis in Bostan Lake basin. Acta Geographica Sinica, 72(9): $1680-1694$.

Muxworthy A R, McClelland E, 2000. Review of the low-temperature magnetic properties of magnetite from a rock magnetic perspective. Geophysical Journal International, 140: 101-114.

Qiu J, 2008. The Third Pole. Nature, 454: 393-396. 
Roberts A P, Cui Y, Verosub K L, 1995. Wasp-waisted hysteresis loops: Mineral magnetic characteristics and discrimination of components in mixed magnetic systems. Journal of Geophysical Research, 100: 17909-17924, doi: 10.1029/95JB00672.

Spiteri C, Kalinski V, Rösler W et al., 2005. Magnetic screening of a pollution hotspot in the Lausitz area, Eastern Germany: Correlation analysis between magnetic proxies and heavy metal contamination in soils. Environmental Geology, 49(1): 1-9.

Sun Xi, Liu Heman, Zhou Tong et al., 2016. Preliminary study on soil fertility and heavy metal concentrations of croplands in Nyingchi valley of Tibet. Soils, 48(1): 131-138. (in Chinese)

Torrent J, Barrón V, 2008. Diffuse reflectance spectroscopy//Ulery A L, Drees R. Methods of Soil Analysis Part 5: Mineralogical Methods. Madison, WI: Soil Science Society of America, Inc.

Verwey E J, 1939. Electronic conduction of magnetite $\left(\mathrm{Fe}_{3} \mathrm{O}_{4}\right)$ and its transition point at low temperature. Nature, 144: $327-328$

Wan X, Kang S C, Li Q L et al., 2017. Organic molecular tracers in the atmospheric aerosols from Lumbini, Nepal, in the northern Indo-Gangetic Plain: Influence of biomass burning. Atmospheric Chemistry and Physics, 17: 8867-8885.

Wang X P, Ren J, Gong P et al., 2016. Spatial distribution of the persistent organic pollutants across the Tibetan Plateau and its linkage with the climate systems: A 5-year air monitoring study. Atmospheric Chemistry and Physics, 16(11): 6901-6911.

Wang X P, Yang H, Gong P et al., 2010. One century sedimentary records of polycyclic aromatic hydrocarbons, mercury and trace elements in the Qinghai Lake, Tibetan Plateau. Environmental Pollution, 158: 3065-3070.

Wu G M, Wan X, Gao S P et al., 2018. Humic-like substances (HULIS) in aerosols of Central Tibetan Plateau (Nam Co, $4730 \mathrm{~m}$ asl): Abundance, light absorption properties, and sources. Environmental Science \& Technology, 52: 7203-7211.

Xiao Cunde, Qin Dahe, Yao Tandong et al., 2000. The global pollution revealed by $\mathrm{Pb}, \mathrm{Cd}$ in the surface snow of Antarctic, Arctic and Qinghai-Xizang Plateau. Chinese Science Bulletin, 45(9): 847-853.

Xie Ting, Zhang Shujuan, Yang Ruiqiang, 2014. Contamination levels and source analysis of polycyclic aromatic hydrocarbons and organochlorine pesticides in soils and grasses from lake catchments in the Tibetan Plateau. Environmental Science, 35(7): 2680-2690. (in Chinese)

Xu B, Cao J, Hansen J et al., 2009. Black soot and the survival of Tibetan glaciers. Proceedings of the National Academy of Sciences, 106(52): 22114-22118.

Yang H D, Battarbee R W, Turner S D et al., 2010. Historical reconstruction of mercury pollution across the Tibetan Plateau using lake sediments. Environmental Science \& Technology, 44: 2918-2924.

Yao Tandong, Piao Shilong, Shen Miaogen et al., 2017. Chained impacts on modern environment of interaction between Westerlies and Indian Monsoon on Tibetan Plateau. Bulletin of Chinese Academy of Sciences, 32(9): 976-984.

Yin Xiufeng, de Foy Benjamin, Wu Kunpeng et al., 2019. Gaseous and particulate pollutants in Lhasa, Tibet during 2013-2017: Spatial variability, temporal variations and implications. Environmental Pollution, 253: 68-77.

Zhang Chunxia, Huang Baochun, Liu Qingsong, 2009. Magnetic properties of different pollution receptors around steel plants and their environmental significance. Chinese Journal of Geophysics, 52(11): 2826-2839. (in Chinese)

Zhang Chunxia, Huang Baochun, Luo Rensong et al., 2007. Magnetic properties of tree ring samples close to a smelting factory and their environmental significance. Quaternary Sciences, 27(6): 1092-1104. (in Chinese)

Zhang F, Yan X D, Zeng C et al., 2012. Influence of traffic activity on heavy metal concentrations of roadside farmland soil in mountainous areas. International Journal of Environmental Research and Public Health, 9(5): 1715-1731.

Zhang Q, Huang J, Wang F et al., 2012. Mercury distribution and deposition in glacier snow over western China. Environmental Science \& Technology, 46(10): 5404-5413.

Zhang Weiling, Zhang Gan, Qi Shihua et al., 2003. A preliminary study of organochlorine pesticides in water and sediments from two Tibetan lakes. Geochimica, 32(4): 363-367. (in Chinese)

Zheng Du, Yao Tandong, 2004. Uplifting of Tibetan Plateau with Its Environmental Effects. Beijing: Science Press. (in Chinese)

Zhu L P, Lv X M, Wang J et al., 2015. Climate change on the Tibetan Plateau in response to shifting atmospheric circulation since the LGM. Scientific Reports, 5(1): 13318, doi: 10.1038/srep13318. 